\title{
Edit Check
}

National Cancer Institute

\section{Source}

National Cancer Institute. Edit Check. NCI Thesaurus. Code C142521.

A process, usually automated, that is used to check the validity of the input in a data field. 